\title{
Seismic Vulnerability in the Himalayan Region
}

\author{
Dr. Harihar Paudyal ${ }^{1}$ and Ananta Panthi ${ }^{2}$ \\ ${ }^{1}$ Reader, Department of Physics, Birendra Multiple Campus, Bhartapur, E-mail:hariharpaudyal@gmail.com \\ ${ }^{2}$ Reader, Department of Physics, Butwal Multiple Campus, Butwal,E-mail:apanthi@hotmail.com
}

\begin{abstract}
The frequently occurring strong earthquakes in the Himalayan region signify the seismic vulnerability in the region. The continued northward movement of Indian plate is generating large amount of stress at the plate boundary which is being released in form of large and great earthquakes $(M \geq 7)$. Absence of such great events in the Himalayan front for last six decades and in some segments for last two centuries envisages the region as a high potential zone for future seismic hazard. In this paper we studied the larger events in the central Himalayan region.
\end{abstract}

Key words: central himalaya, large earthquakes, seismic hazards

\section{Introduction}

According to plate tectonic theory, the Earth consists of a mosaic of six major and several smaller plates which are in relative motion. These plates represent the rigid crust and upper mantle, of $\sim 50-100 \mathrm{~km}$ thick. Large earthquakes frequently occur at the margins of these plates due to sudden release of strain energy which has built up over a period of time. The Himalaya is located at the boundary between the Indian and Eurasian plates. The northward conversing India induced crustal shortening that is accommodated not only in the formation of the Himalayas and Tibet but it also distributed throughout the Asian crust including the region north of the Tibetan plateau.

The Himalaya Mountains, form a well defined arc, and extend for $\sim 2500 \mathrm{~km}$ from Nanga Parbat $(8215 \mathrm{~m})$ in west-northwest to Namcha Barwa $(7755 \mathrm{~m})$ to the east-northeast. The geodynamics of the Himalayan region has produced a number of complex tectonic provinces due to continued action of converging stress field in the last fifty-five million years since collision. Closure of ancient Tethys Ocean and folding into mountain occurred during the periods from Cretaceous to Tertiary. Since the collision, Indian plate continue to push northward till present at an average rate $\sim 50 \mathrm{~mm} /$ year. The seismic activity in the Himalayan region is confined to the plate boundary areas and is associated with collision and the under-thrusting of the Indian plate beneath the Eurasian plate (Molnar and Tapponnier, 1978). Richter (1958) pointed that, the great thrusts of the Himalaya are now apparently quiescent for large earthquakes but the foothill shows geologically very recent faulting and thrusting on a large scale.

\section{Large earthquakes in the Himalaya}

Earthquakes of large, medium and small magnitudes occur in this region since the historical past (Oldham, 1882; Gutenberg and Richter, 1954; Chandra 1992). Molnar and Chen (1982) have explained the seismicity of Eastern Asia as an indicative of active deformation in a wide region between Indian and Eurasian plates and is directly associated to the convergence of these plates. Himalayan belt was rocked by four great earthquakes (1897 Assam, 1905 Kangra, 1934 Nepal-Bihar border and 1950 Assam) within fifty-five years (1897-1950) and large number of strong earthquakes caused huge loss of lives and property.

In the region, Khattri (1987), using seismicity data from 1800 to 1982 , identified a seismic gap between the rupture zones of two great earthquakes of Kangra (1905) and Nepal-Bihar (1934), termed as Central Gap, (Fig. 1) in which no great earthquake $(\mathrm{M} \geq 8)$ has been experienced so far at least for last 200 years. He concluded that this region is a potential site for future great seismic activity. Current seismicity pattern shows that the rate of occurrence of large earthquakes is evidently too low to accommodate Indo/Tibetan slip which must therefore be accommodated by creep or occasional great earthquakes. Creep processes do not appear to be significant at least in central Nepal region (Bilham et al., 1995). 


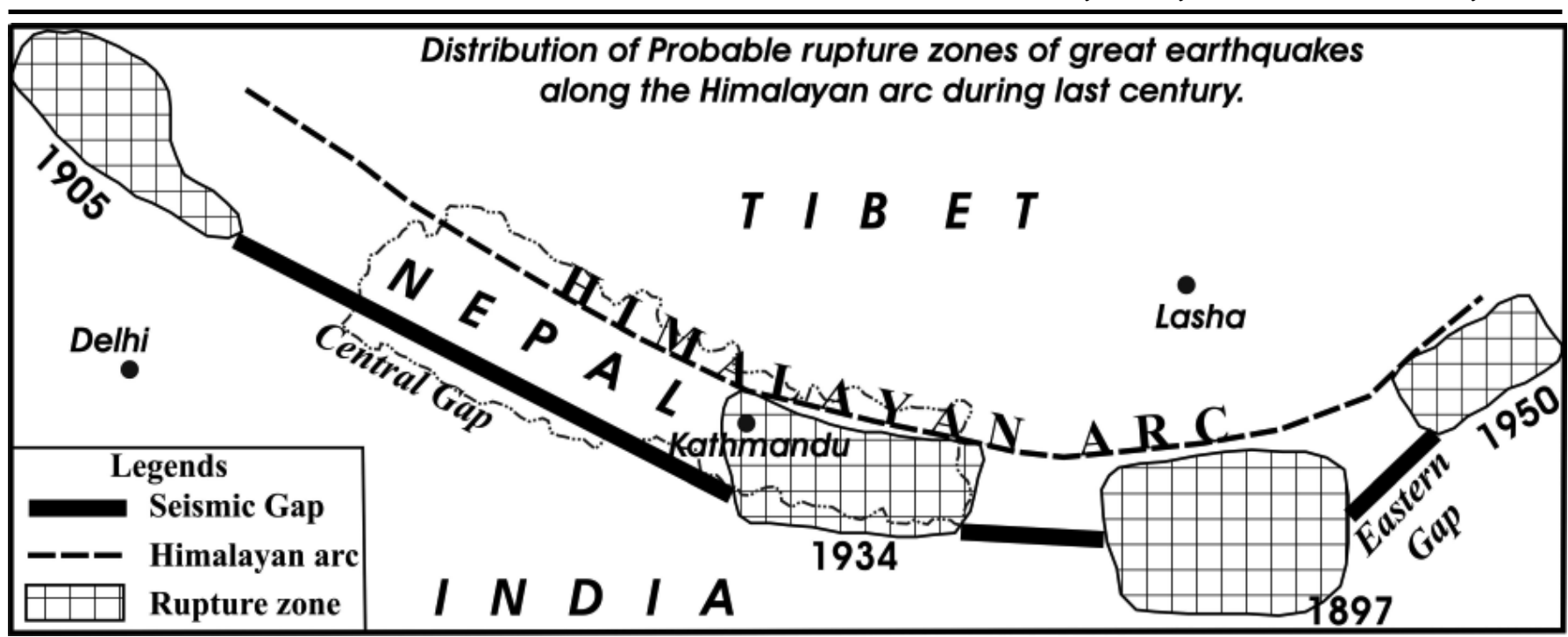

Fig. 1: Distribution of probable rupture zones of the 1897 (Shillong), 1905 (Kangra), 1934 (Nepal-Bihar) and 1950 (Assam) great earthquakes along the Himalayan arc (modified from Pandey et al., 1999). The region between the 1905 and 1934 earthquake and the region between 1897 and 1950 earthquakes are termed as central and eastern gap respectively and considered potential zones for future seismic hazard.

Based on the distribution and occurrence date of earlier large earthquakes in the Himalayas Bilham et al. (2001) estimated the amounts of potential slip accumulated by constant plate motions and concluded that large earthquakes in Himalaya are overdue, even if a substantial fraction of the plate motion is absorbed by seismic creep. Considering probable ruptures of $150 \mathrm{~km}$ segments of the Himalayan plate boundary at seven positions, Kashmir, Dehra Dun, Garhwal, West Nepal, Kathmandu, Bhutan and Assam, where sufficient elastic energy is believed to be accumulated for magnitude eight earthquakes, Wyss (2005) estimated potential losses quantitatively that may be caused by future great earthquakes and infer that as many as 150,000 people may die, 300,000 may be injured and typically $\sim 3,000$ settlements will be affected in a single such great event. The estimated human loss due to great earthquake along the Himalayan boundary shows if such event occur around the Kathmandu and west Nepal the loss will be 21-42 and 11-22 thousands respectively and number of injured may cross 45-86 and 24-53 thousands respectively (Wyss, 2005). In such cases the number of settlements expected to experience shaking of intensity VII will be 330 and 370 respectively.

\section{Large earthquakes in the Central Himalaya}

Central Himalaya, which has been sites of several large earthquakes including 1934 great earthquake (M 8.4) during the last century is seismically one of the active domains in the Himalayan arc. Nepal located at the central part of the Himalaya represents one of the active seismic zones in the Himalaya. There are historical indications that Kathmandu has been struck by repeated severe earthquakes in the past (Rana, 1935). Major destructions, probably of seismic origin, were reported in 1223,1255 , 1344, 1408, 1681, and 1833 and other major events located within Nepal Territory in the first half of the last century were in 1916, 19341936 and moderate size but devastating recent earthquakes are Bajhang 1980 (Ms 6.5), Udaypur 1988 (Ms 6.6) and Chamoli 1999 (Ms 6.6). The eastern and western portions of the Himalaya are more active than the central part.

The annual seismic energy release for the period 1963 to 2006 shows a gradual increasing trend towards northwest and north-northeast from the epicenter of 1934 great earthquake leaving a gap with very low seismic energy release in the western Nepal region (Paudyal and Singh, 2008). Similarly, the area between the 1934 and 1950 events stands out as another seismic gap (Fig. 1) that has not produced any major earthquake in the historical times. There is a very high probability of a mega-event in these seismic gaps in near future (Bilham et al., 2001). Eight large earthquakes with $\mathrm{M} \geq 7$ have occurred in Central Himalayan region from 1803 to 1936 including the great earthquake 


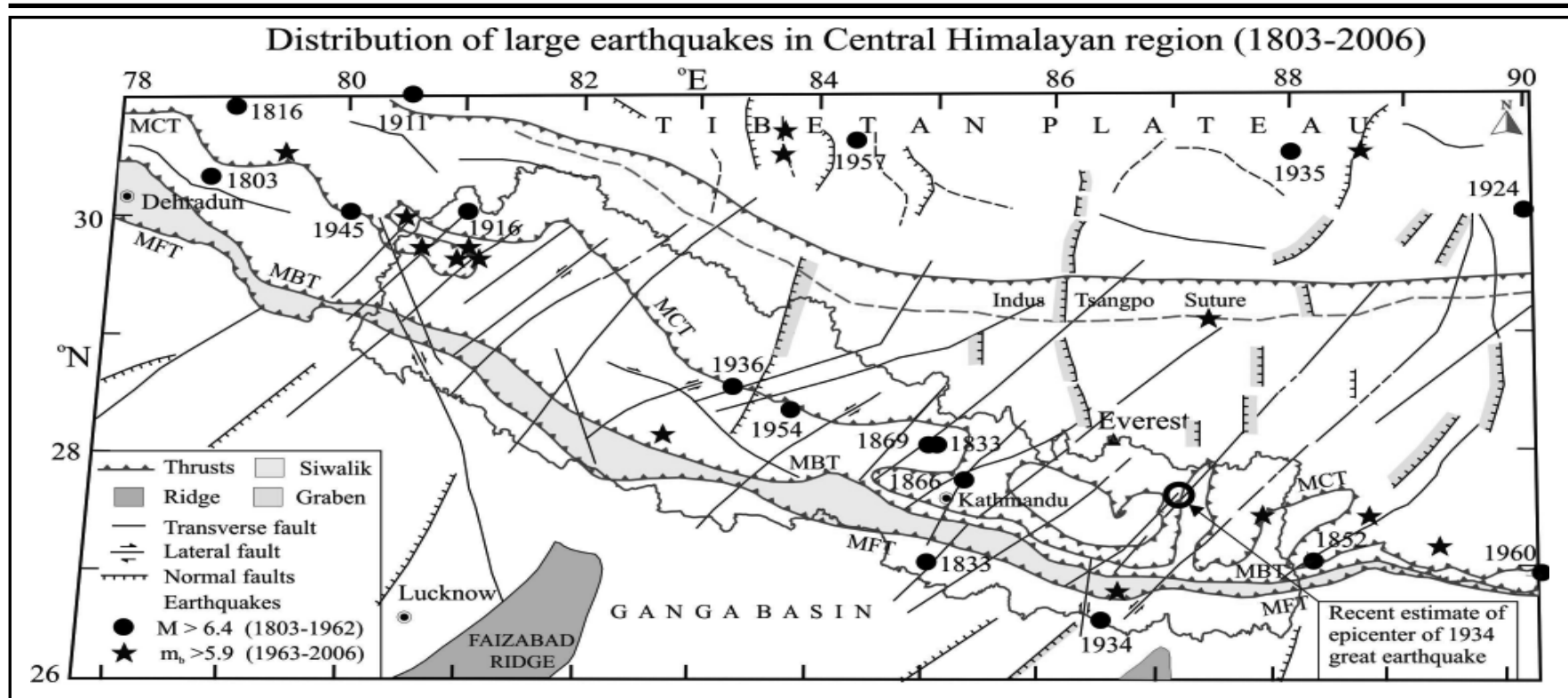

Fig. 2: Spatial distribution of large earthquakes for $\mathrm{m}_{\mathrm{b}} \geq 6$ during the period 1803 to 2006 that occurred in Central Himalayan arc and its adjoining regions. The year in which event was occurred is also given for the larger events.

of 1934 (Fig. 2) whereas no such earthquake has occurred so far since 1936 as it is evident from the temporal pattern of large earthquakes from 1803 to 1962 (Fig. 3).

The Central Himalayan Frontal Arc has been the site of several large earthquakes of $M \geq 7$ and these occurred

in the order of high- low-high-low phases of seismicity from 1803 to 2006. Temporal pattern of large earthquakes occurred (Fig. 3) shows that the first high active phase continued for 37 years from 1833 to 1869 which marked occurrence of four earthquakes of $M$ $\geq 7$. This active phase was followed by a quiescence period of 46 years with extremely low seismic activity. The second high active phase was for a comparatively shorter period for 21 years only (1916-1936) with the occurrence of three large earthquakes including 1934 great earthquake (Fig. 2). It is also evident that about 30 earthquakes have also occurred in the magnitude range 6-6.9 during the second active phase till 1966. A low seismicity phase is quite evident since 1967 till present for about 42 years during which only eight earthquakes in the magnitude range 6-6.6 occurred. Most of these large earthquakes are probably associated with the MBT in thrust faulting environment (Fig. 2) signifying subduction of Indian plate below the Tibetan plate.

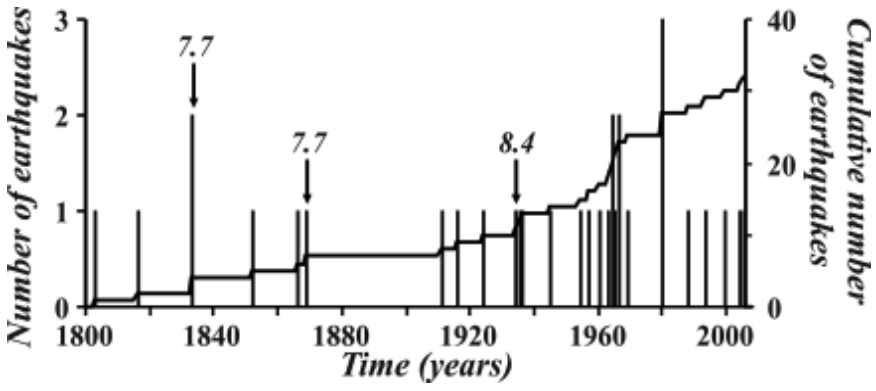

Fig. 3: Temporal patterns of large earthquakes in Nepal and its adjoining regions in Central Himalaya from 1803-1962 for $M \geq 6.5$ and from 1963-2006 for $m_{b} \geq 6$.

\section{Discussion}

The Himalaya region represents the major part of the collision boundary, where two continental plates collide and as a result huge mountain range is formed, this produces a wide zone of deformation and resulting seismic activity. It is evident that a major portion of the central seismic gap of Himalaya lies within the territory of Nepal (Fig. 1) representing high seismic hazard. Nepal stands at eleventh with respect to relative vulnerability to earthquake. Upreti, (2006) reported the most common natural disasters in Nepal are, landslides, debris flows, floods, earthquakes, snow avalanches, glacial lake outburst floods, hailstorms, thunderbolts, cold waves, hot waves and epidemics. Because of the suddenness and high energy release in a very short span of time (in few seconds), earthquake has high degree of severity among natural disasters. The 
entire Himalayan region as a whole represents a vulnerable for seismic hazard in near future. vulnerable region for earthquake.

In the light of above, scientific study towards the search of medium and short-term precursors is urgently required for this region. Such studies may help to reduce the worst effect of impending earthquake. Although the time of future earthquakes is unknown, there is no doubt that great earthquakes $(\mathrm{M} \geq 8)$ will happen along the front of the Himalaya which may produce large scale damage in the surrounding areas. Obviously, humans will never be capable to avoid the occurrences of natural phenomena completely. Nevertheless, scientists are able to achieve a better understanding of the complex mechanisms that cause such disasters and to share their knowledge to related agencies in order to be prepared to handle with such extreme disaster.

Generally, it is well accepted that the elements for a valid earthquake prediction are as follows:

1. Location \pm Uncertainty

2. Size \pm Uncertainty

3. Occurrence time \pm Uncertainty

4. Probability (Allen, 1976).

Current understanding on theory of dynamics of seismic activity can predicts the parameters 1, 2 and 4 up to some extent, it is argued in the scientific community that the precise timing of individual earthquakes inherently unpredictable.

\section{Conclusion}

The earthquakes are the most serious and devastating among all the natural hazards in Himalayan region. Based on geodetic data and seismic studies many researches pointed out that sufficient amount of stress accumulated in the Himalayan plate boundary that may trigger great earthquake at any time. The temporal and spatial distribution of large earthquakes in the Central Himalaya region shows non-uniform distribution pattern. A number of possible locations were delineated for such great event which may have rupture zone of comparable size of that of past great earthquakes in the region. The region is

\section{References:}

Allen CR, Bull. Seismo. Soc. Am., 66, 2069-2074, 1976.

Bilham R, Bodin P, and Jackson M, Jour. of Nepal Geol. Soc., 11, 73-78, 1995.

Bilham R, Gaur VK, and Molnar P, Himalayan seismic hazard, Science, 293, 1442-1444, 2001.

Chandra, U, Seismotectonics of Himalaya, Current Science, 62, 40-71, 1992.

Gutenberg, B and Richter, CF, Seismicity of the Earth and Associated Phenomena, Hafner Pub., 1954.

Khattri KN, Tectonophysics, 138, 79-92, 1987.

Molnar P and Tapponnier P, Journal of Geophysics, 83, 5361-5375, 1978

Oldham, T, Memoir. Geol. Surv. India, 19, 163-215, 1882.

Pandey MR, Tandukar RP, Avouac JP, Vergne J and Heritier Th, Jour. Asian Earth Sci., 17, 703-712, 1999.

Paudyal H and Singh HN, Journal of Scientific Research, 52, 19-31, 2008.

Rana, BS, Nepalko Mahaghukampa, Gorganesh Press, 1935.

Richter CF, Elementary Seismology, W.H. Freeman and Co., San Francisco, pp. 764, 1958.

Upreti BN, Policy paper-27, Eco. Policy Network, Ministry of Finance, Gov. of Nepal, pp.91, 2006.

Wyss M, Human losses expected in Himalayan earthquakes, Natural Hazards, 34, 305-314, 2005. 